Check for updates

Cite this: RSC Adv., 2019, 9, 4054

\title{
The preparation of hydroxyapatite from unrefined calcite residues and its application for lead removal from aqueous solutions $\dagger$
}

\author{
Elena Bernalte, $\stackrel{+}{*}^{* a}$ Joanna Kamieniak, ${ }^{a}$ Edward P. Randviir, (D) *b Álvaro Bernalte- \\ García $^{c}$ and Craig E. Banks (DD ${ }^{a}$
}

Calcite originating from waste treatment technologies was utilised for the chemical precipitation of hydroxyapatite (HAP). The physicochemical properties of the as-synthesised-HAP was fully characterised using FT-IR, BET, SEM and TEM, confirming its crystal structure and formation of high purity HAP by $\mathrm{XRD}$. The product was employed for removal of lead from aqueous media at $\mathrm{pH}$ 5.0, achieving almost $80 \%$ of the adsorption in the first $5 \mathrm{~min}$ and a maximum adsorption capacity for $\mathrm{Pb}^{2+}$ of $224.4 \mathrm{mg} \mathrm{g}^{-1}$. A contact time of $40 \mathrm{~min}$ was required to achieve equilibrium with $\mathrm{Pb}^{2+}$ uptake of $98 \%$. The kinetics of the cation exchange of HAP from calcite were predicted using integrated rate laws, revealing a pseudosecond order cation exchange process with a rate constant of $\left.6.84 \times 10^{-4} \mathrm{~g} \mathrm{(mg} \mathrm{min}\right)^{-1}$. All obtained results are benchmarked against a control HAP sample simultaneously derived from eggshells, which were demonstrated to offer slower kinetics of cation exchange $\left(4.82 \times 10^{-4} \mathrm{~g}\left(\mathrm{mg} \mathrm{min}^{-1}\right)\right.$ and almost half the maximum adsorption capacity $\left(129.1 \mathrm{mg} \mathrm{g}^{-1}\right)$. The results showed that hydroxyapatite synthesised from calcite waste represents a low-cost material for the adsorption of hazardous $\mathrm{Pb}^{2+}$ in contaminated waters and a promising alternative for heavy metals remediation in aquatic environments.

Received 1st June 2018

Accepted 23rd January 2019

DOI: $10.1039 / \mathrm{c} 8 \mathrm{ra0} 4701 \mathrm{~d}$

rsc.li/rsc-advances methods in this field are still required in order to achieve targets set out by central government, with a particular focus on materials that are either difficult to recycle, or don't have existing recycling routes. Aside from this, solid residues, precipitates, and minerals accumulating within advanced waste management technologies are yet another issue with practical application of the principles set out by the WFD.

Calcite is an example of an unwanted material formed as a result of an advanced waste management systems. It is very well-known that calcite $\left(\mathrm{CaCO}_{3}\right)$ is formed in many water processes causing blockages and technology failure in heat exchangers, tanks, reverse osmosis systems, and pipework within industrial environments. It is an off-white mineral that is extremely hard, crystalline, and highly pure. The EU estimates that calcite issues in processing technology (such as heat exchangers) can cost up to $0.25 \%$ of a nation's GDP in the industrialised world. ${ }^{2}$ Developing methods to feed these materials back into the supply chain will help close the loop to the 'circular economy'.

Hydroxyapatite ( $\left.\mathrm{HAP}, \mathrm{Ca}_{5}\left(\mathrm{PO}_{4}\right)_{3} \mathrm{OH}\right)$ is an inorganic material that has been extensively studied due to its valuable characteristics and has been mostly employed in biomedical applications as it exhibits structural similarities to human bones and teeth. Besides various dental, orthopaedic and drug delivery fields that utilise HAP for its recognised biocompatibility, it has been also described as an excellent catalyst, because of its hydrophilic properties, structural stability and bifunctionality, 
as summarised in a review by Gruselle. ${ }^{3}$ In recent years, however, attention has turned towards the utilisation of HAP as a sorbent material for environmental pollutants. In particular, HAP has been successfully investigated for the adsorption of heavy metals, due to its low water solubility and high stability under oxidising and reducing conditions, giving rise to its excellent adsorption capabilities. ${ }^{4,5}$ In view of chemical synthesis of HAP, it essentially requires a source of calcium and phosphate. Thus, exploring innovative and simpler approaches, employing inexpensive recycled calcium materials and using reduced energy consumption protocols to synthesise such a benign material presents a worthwhile research challenge. Besides conventional synthetic chemical routes, a plethora of waste materials that attain high calcium content have been successfully utilised as a calcium source in the preparation process of HAP, such as mussel shells, ${ }^{6-9}$ eggshells, ${ }^{10-13}$ kina shells, ${ }^{14}$ fish bones or scale, ${ }^{15,16}$ gypsum, ${ }^{17-21}$ ash of poultry waste, ${ }^{20}$ aquaculture wastewater, ${ }^{22}$ biomass ashes, ${ }^{23}$ oyster shells, ${ }^{24}$ calcium sulfite from production of agrichemicals, ${ }^{25}$ abalone shells, ${ }^{26}$ cattle bones ${ }^{27}$ and mystery snail shells. ${ }^{28}$

Heavy metals' pollution of aquatic environments as a consequence of anthropogenic activities has drawn international attention due to their persistency, non-biodegradability, bioaccumulation and toxicity. ${ }^{29}$ Lead $\left(\mathrm{Pb}^{2+}\right)$ is one of the most ubiquitous hazardous contaminants in aquatic environments of which presence at certain concentrations may cause irreparable damage for the environment, including flora and fauna, and humankind after consuming contaminated water. $^{30}$ Consequently, the development of technology for the efficient removal of heavy metals from contaminated waters is a necessity of global interest.

This paper explores the utilisation of calcite waste, which is already in existence as common waste by-product, as a calcium source in the synthesis of hydroxyapatite (HAP). Calcium carbonate was extracted from waste calcite in acidic media and directly employed in the standard wet precipitation protocol to obtain stoichiometric HAP. The obtained material was benchmarked against eggshells-derived HAP that is widely reported in the literature. Resulting materials together with raw calcium precursors were fully characterised for their physicochemical properties and applied to remove hazardous $\mathrm{Pb}^{2+}$ from aqueous solutions.

\section{Experimental}

\subsection{Materials and chemicals}

All chemicals were obtained from Sigma-Aldrich and were used as received without any further purification, such as $\mathrm{HCl}(37 \%$, $\geq 99.8 \%, 1.2 \mathrm{~g} \mathrm{~mL}^{-1}$ at $\left.25{ }^{\circ} \mathrm{C}\right), \mathrm{HNO}_{3}(70 \%$ purified by redistillation, $\geq 99.999 \%, 1.413 \mathrm{~g} \mathrm{~mL}-1$ at $\left.20{ }^{\circ} \mathrm{C}\right),\left(\mathrm{NH}_{4}\right)_{2} \mathrm{HPO}_{4}$ $(\geq 98 \%), \mathrm{NH}_{4} \mathrm{OH}\left(28.0-30.0 \%, 0.9 \mathrm{~g} \mathrm{~mL}^{-1}\right.$ at $\left.25{ }^{\circ} \mathrm{C}\right), \mathrm{NaCl}$ $(\geq 99.5 \%), \mathrm{Pb}\left(\mathrm{NO}_{3}\right)_{2}(\geq 99.999 \%)$. All solutions were made by using deionised water with a resistivity not less than 18.2 $\mathrm{M} \Omega \mathrm{cm}$. Glassware employed for the lead adsorption experiments was thoroughly conditioned for trace analysis i.e. soaked in hot nitric acid at $10 \%$ for $48 \mathrm{~h}$, rinsed with ultrapure water, dried and kept in hermetic plastic bags until used.
Calcite is a common mineral found to build up inside water treatment technologies as a result of high levels of calcium ions within hard water. The process of calcium spontaneously depositing on a surface is commonly known as scale deposition, and can affect chemical technology significantly if not managed effectively. The resulting "scaling" of treatment technologies can cause severe process hindrance and downtime through increasing pipe pressure and blockages. This work takes advantage of a waste treatment process suffering from a "downtime" period, where calcite was responsible for its closure. The calcite was extracted from a process water tank suffering from severe calcite scale deposition. The tank was part of an industrial anaerobic digestion process for the treatment of municipal solid waste. The mineral was sheet-like and very brittle, hence was extracted from the tank walls using a hammer and chisel. The calcite was dried at $105^{\circ} \mathrm{C}$ for 18 hours before use.

\subsection{Preparation of calcium precursors from waste materials}

Two different waste materials were used, calcite waste and eggshells, as a calcium precursor for the synthesis of HAP and pre-treated as follows: calcite was first manually shattered using a hammer, then crushed into a fine powder with a vibratory micro mill (Fritsch analysette 3 Spartan, 50 W, 50-60 Hz). The eggshells were first thoroughly cleaned with deionised water and then soaked in concentrated $\mathrm{NaCl}(1 \mathrm{M})$ solution for $10 \mathrm{~min}$ to remove the inner membrane layer. After drying at room temperature, crushed eggshells were ground to a fine powder using a planetary ball mill (Retsch PM100) equipped with Teflon jars and zirconia grinding balls, for $10 \mathrm{~min}$ at $300 \mathrm{rpm}$ and $10 \mathrm{~min}$ at $500 \mathrm{rpm}$, consecutively. Finally both materials were homogenised using a $250 \mu \mathrm{m}$ sieve (Retsch) and stored in the desiccator chamber. This ensured homogeneous particle size for both materials, ensuring that the materials were as comparable as possible.

Pre-treated waste powders $(8.51 \mathrm{~g})$ were dissolved in a $100 \mathrm{~mL}$ solution of $\mathrm{HCl}(37 \%)$ and water in the molar ratio $1: 3$ and stirred for 2 hours at room temperature to extract calcium. The obtained solutions were filtered in a vacuum system to eliminate any possible residue and the resultant filtrates were kept at room temperature until used as calcium precursors to perform the synthesis of HAP.

\subsection{Synthesis of hydroxyapatite (HAP) from waste materials}

A solution of $\left(\mathrm{NH}_{4}\right)_{2} \mathrm{HPO}_{4}(0.18 \mathrm{M}, 50 \mathrm{~mL})$ was stirred at room temperature in a beaker with the extracted calcium precursor from waste powders (see Section 2.2) added dropwise, resulting in a "milky" suspension of HAP. During the precipitation process, the $\mathrm{pH}$ was maintained within the range 9.8-9.9 through the addition of small amounts of $\mathrm{NH}_{4} \mathrm{OH}(28 \%)$. The mixture was stirred overnight $(16 \mathrm{~h})$ at room temperature $(20 \pm$ $1{ }^{\circ} \mathrm{C}$ ) using a magnetic stirring bar. The final precipitate obtained was filtered, cleaned alternately with water and ethanol three times, dried in the oven at $60{ }^{\circ} \mathrm{C}$ for 2 hours and calcined at $550{ }^{\circ} \mathrm{C}$ for a further 6 hours. The resulting HAP was manually powdered using a pestle and mortar. The same procedure was repeated to synthesise eggshells-derived HAP. 


\subsection{Characterisation techniques}

Microscopic images were recorded using a Supra 40VP (Carl Zeiss Ltd) scanning electron microscope (SEM) and JEOL 3000F using field emission gun instrument at $300 \mathrm{kV}$ high resolution transmission electron microscopy (HR-TEM). Semi-quantitative chemical analysis was performed by X-ray fluorescence (XRF) via Rigaku NexCG 1220 and energy-dispersive X-ray spectroscopy (EDAX) using an Apollo 40 SDD instrument. Fourier transform infrared spectroscopy (FT-IR) was performed via Nicolet 380 Smart iTR using diamond attenuated total reflection (ATR) spectrometer. X-ray diffraction (XRD) was conducted in powder spinning mode at ambient conditions using a Panalytical X'Pert Powder diffractometer with $\mathrm{Cu} \mathrm{K} \alpha$ radiation $(\lambda=$ $1.5406 \AA$ A). All powder diffraction patterns were recorded with step size 0.052 and step time $200 \mathrm{~s}$, using an X-ray tube operated at $40 \mathrm{kV}$ and $30 \mathrm{~mA}$ with fixed $1 / 2^{\circ}$ anti-scatter slit. XRD patterns of waste materials and HAP were benchmarked against known XRD standards (JCPDS 05-0586 and JCPDS 09-0432 for $\mathrm{CaCO}_{3}$ and HAP, respectively). Nitrogen adsorption/desorption measurements were carried out using a Micromeritics ASAP 2020 Surface Analyser at $-196^{\circ} \mathrm{C}$. Samples were degassed under vacuum $\left(p<10^{-3} \mathrm{~Pa}\right)$ for 3 hours at $300{ }^{\circ} \mathrm{C}$ prior to analysis. BET surface areas of the samples were calculated in the relative pressure range $0.05-0.30$ and pore volume was calculated at relative pressure of 0.999 . Calcium content in the extracted calcium precursor solutions as well as lead remaining in the solution after performing adsorption experiments on synthesised HAP were determined by inductively coupled plasma optical emission spectroscopy (ICP-OES) using Thermo Scientific iCAP 6300.

\subsection{Adsorption of lead $\left(\mathrm{Pb}^{2+}\right)$}

The adsorption of $\mathrm{Pb}^{2+}$ was conducted by adding synthesised HAP $(0.025 \mathrm{~g})$ into a set of conical flasks with $\mathrm{Pb}\left(\mathrm{NO}_{3}\right)_{2}$ (220 ppm, $25 \mathrm{~mL}$ ). The $\mathrm{pH}$ of the initial $\mathrm{Pb}^{2+}$ solution was adjusted to 5.0 using $\mathrm{NaOH}(0.01 \mathrm{M})$ and/or $\mathrm{HNO}_{3}(0.01 \mathrm{M})$ as required. Resulting mixtures were placed on a mini orbital shaker (Stuart SSM1) and batch adsorption experiments were performed at room temperature $\left(20 \pm 1{ }^{\circ} \mathrm{C}\right)$ with a constant speed of $200 \mathrm{rpm}$. After adsorption, the contents of each conical flask were filtered under vacuum at different time intervals in the range of 0 to $300 \mathrm{~min}$ and the filtrates were diluted with $\mathrm{HNO}_{3}(5 \%)$ for the determination of residual $\mathrm{Pb}^{2+}$ concentration by ICP-OES. The $\mathrm{Pb}^{2+}$ adsorption capacity of HAP $\left(q_{t}\right)$ obtained from waste materials was calculated according to eqn (1):

$$
q_{t}=\frac{\left(C_{0}-C_{t}\right) V}{m}
$$

where $q_{t}$ is the amount of $\mathrm{Pb}^{2+}$ adsorbed on the HAP $\left(\mathrm{mg} \mathrm{g}^{-1}\right)$, $C_{0}$ and $C_{t}$ are the $\mathrm{Pb}^{2+}$ concentration before and after adsorption $\left(\mathrm{mg} \mathrm{L}^{-1}\right), V$ is the volume of solution $(L)$ and $m$ is the weight of HAP used in the adsorption experiment $(g)$.

The kinetics of cation exchange on HAP were calculated using the function method of simple integrated rate laws. The pseudo-first order kinetic model was investigated using the Lagergen equation, ${ }^{\mathbf{1 0}}$ expressed as eqn (2), which describes the adsorption rate of the material based on the adsorption capacity: ${ }^{19}$

$$
\log \left(q_{\mathrm{e}}-q_{t}\right)=\log q_{\mathrm{e}}-\frac{K_{1}}{2.303} t
$$

where $q_{t}$ is the amount of adsorbed $\mathrm{Pb}^{2+}\left(\mathrm{mg} \mathrm{g}^{-1}\right)$ at any given time $t(\mathrm{~min}), q_{\mathrm{e}}$ is the amount of $\mathrm{Pb}^{2+}$ adsorbed $\left(\mathrm{mg} \mathrm{g}^{-1}\right)$ at equilibrium and $K_{1}$ is the pseudo-first order reaction rate constant for adsorption $\left(\mathrm{min}^{-1}\right)$. The pseudo-second order reaction rate equation was described by the eqn (3):

$$
\frac{t}{q_{t}}=\frac{t}{q_{\mathrm{e}}}+\frac{1}{K_{2} q_{\mathrm{e}}{ }^{2}}
$$

where $q_{t}$ is the amount of adsorbed $\mathrm{Pb}^{2+}\left(\mathrm{mg} \mathrm{g}^{-1}\right)$ at any given time $t(\mathrm{~min}), q_{\mathrm{e}}$ is the amount of $\mathrm{Pb}^{2+}$ adsorbed $\left(\mathrm{mg} \mathrm{g}^{-1}\right)$ at equilibrium and $K_{2}$ is the second order reaction rate constant for adsorption ( $\left.\mathrm{g}(\mathrm{mg} \mathrm{min})^{-1}\right)$.

\section{Results and discussion}

\subsection{Characterisation of raw waste materials as calcium precursors}

First considered is the physicochemical characterisation of both waste materials using the methods described in Section 2.4. Calcite and eggshells were pre-treated as described in the Section 2.2 to obtain fine powders, before performing the chemical pre-treatment for calcium extraction. As shown in Fig. ESI 1A, $\dagger$ SEM images revealed highly agglomerated and irregular surface of eggshells. It is interesting to note, that similar characteristics were also observed in the calcite (Fig. ESI $1 \mathrm{~B} \dagger$ ), which suggests that the calcite possessed similar physical structure to that of eggshells.

Attention was turned to the investigation of the chemical composition of raw eggshells and calcite waste materials via XRF analysis. As summarised in Table 1, the results obtained confirmed an expected high calcium content in eggshells, which corresponded to $41.9 \%$. A near identical high concentration of calcium was also detected in the waste mineral that was found to be $40.6 \%$. Apart from calcium, minor impurities were identified in both materials, including $\mathrm{Mg}, \mathrm{Al}, \mathrm{Si}, \mathrm{P}, \mathrm{S}, \mathrm{Fe}$, $\mathrm{Cl}$ and $\mathrm{Mn}$ that are present at insignificant concentrations compared to $\mathrm{Ca}$. It is also noted that $\mathrm{Pb}$ was not observed in significant levels within either material (0.0024 wt\%).

Following chemical characterisation, XRD analysis was next performed to investigate the crystal structure of the raw materials. As presented in Fig. ESI $2, \dagger$ the obtained diffraction patterns for both materials showed all peaks that clearly corresponded to pure calcite $\left(\mathrm{CaCO}_{3}\right)$ (JCPDS 05-0586). This was an expected result for eggshells, however great similarities were identified in the pattern obtained for the extracted calcite, and a higher diffraction intensity was observed for the calcite when compared to eggshells. Furthermore, the observed patterns did not display any secondary phases present in both materials, at the same time excluding any major impurities present that could cause a detrimental effect in further synthesis.

Subsequently, spectral characterisation of the waste products was performed via FT-IR studies, using attenuated total 
Table 1 Results obtained from the analysis of raw eggshells and calcite by XRF

\begin{tabular}{|c|c|c|c|c|c|c|c|c|c|}
\hline & $\mathrm{Ca}(\%)$ & $\mathrm{Mg}(\%)$ & $\mathrm{Al}(\%)$ & Si $(\%)$ & P (\%) & $\mathrm{S}(\%)$ & Fe $(\%)$ & $\mathrm{Cl}(\%)$ & Mn (\%) \\
\hline & $41.90 \pm 0.097$ & $0.204 \pm 0.025$ & $0.088 \pm 0.0202$ & $0.177 \pm 0.002$ & $0.175 \pm 0.001$ & $0.12 \pm 0.000$ & $0.010 \pm 0.000$ & $0.077 \pm 0.000$ & $0.004 \pm 0.000$ \\
\hline Calcite & $40.60 \pm 0.092$ & $0.554 \pm 0.037$ & $0.165 \pm 0.003$ & $0.472 \pm 0.003$ & $0.163 \pm 0.001$ & $0.491 \pm 0.001$ & $0.327 \pm 0.003$ & $0.066 \pm 0.000$ & $0.191 \pm 0.003$ \\
\hline
\end{tabular}

reflectance (ATR) to indicate chemical bonding within the materials. As shown in Fig. ESI $3, \uparrow$ the most intense peak present at $1398 \mathrm{~cm}^{-1}$ corresponded to $\nu_{3}$ asymmetric stretching mode of carbonate. The peak observed at $872 \mathrm{~cm}^{-1}$ indicated asymmetric deformation of $\mathrm{CO}_{3}{ }^{2-}$ followed by the peak at $712 \mathrm{~cm}^{-1}$ associated with symmetric deformation of $\mathrm{CO}_{3}{ }^{2-} \cdot{ }^{31}$ The absence of any other significant peaks is in agreement with other studies performed that excluded any other phases or impurities and confirmed that calcite is the main component of the tested waste materials.

After full characterisation, both powders were separately treated with hydrochloric acid to extract the calcium into solution. The final concentration of Ca was accurately determined using ICP-OES. Based upon those results, the exact amount of phosphate precursor $\left(\left(\mathrm{NH}_{4}\right)_{2} \mathrm{HPO}_{4}\right)$ required to precipitate stoichiometric HAP was calculated in each case in order to maintain molar ratio of $\mathrm{Ca} / \mathrm{P}$ of 1.67 during the synthesis process.

\subsection{Synthesis and characterisation of HAP from waste materials}

Next considered is the structure and characteristics of the synthesised HAP materials. The mechanism of HAP formation is described according to eqn (4), where HAP is formed via the reaction of calcium precursors, in the form of $\mathrm{CaCO}_{3}$, extracted from the waste materials at the conditions described in Section 2.2.

$$
\begin{aligned}
& 5 \mathrm{CaCO}_{3}+3\left(\mathrm{NH}_{4}\right)_{2} \mathrm{HPO}_{4}+2 \mathrm{NH}_{4} \mathrm{OH} \rightarrow \mathrm{Ca}_{5}\left(\mathrm{PO}_{4}\right)_{3} \mathrm{OH}+ \\
& 4\left(\mathrm{NH}_{4}\right)_{2} \mathrm{CO}_{3}+\mathrm{CO}_{2}+2 \mathrm{H}_{2} \mathrm{O}
\end{aligned}
$$

This novel approach utilised calcite materials directly from the source, without further purification or pre-treatment, instead of using refined material since this work recycles the waste calcite in order to obtain an advantageous material that can be employed in many different ways. This allows insights into the direct valorisation of a waste material at a reduced cost. Moreover, this synthetic approach is attractive due to an extremely high yield obtained from both products, which corresponded to $99.2 \%$ and $95.7 \%$ when calcite and eggshells were utilised, respectively.

The obtained HAP materials were characterised via SEM, which revealed a highly agglomerated crystalline HAP structure, as observed in Fig. 1. It is interesting to note, that as exhibited in SEM micrographs smaller particles were formed on the surface of HAP synthesised from eggshells. EDX analysis was subsequently performed to detect impurities formed within the precipitated HAP products. Excluding elements anticipated in HAP i.e. Ca, P and $\mathrm{O}$, there were insignificant presence of other species within the products. In the mineral derived HAP the main impurities were $\mathrm{Fe}, \mathrm{Cl}, \mathrm{Mg}, \mathrm{Mn}, \mathrm{S}, \mathrm{Al}$ and $\mathrm{Si}$. The chlorine species were associated with residues from $\mathrm{HCl}$ employed to extract $\mathrm{Ca}$, whereas all other elements were present in the raw mineral before any treatments (Table 1) and are likely intercalated within the structure due to trace ions in the waste water process. However, such low wt $\%$ of all elements ( $<1 \mathrm{wt} \%$ ) were considered as insignificant. The eggshells-derived HAP exhibited $\mathrm{Mg}$ and $\mathrm{Cl}$ from the same origins. The structure of HAP was further studied by HR-TEM. As depicted in Fig. 2C, the obtained HAP particles were highly ordered hexagonal shaped when HAP was prepared using calcite. At higher magnification (shown within Fig. 2D), very clear repeated structural arrangements of HAP were observed, that indicated columns of calcium ions and oxygen atoms originating from phosphate groups, that are situated parallel to the hexagonal axis. This is a typical feature of HAP, which is demonstrated previously appearing as "light" coloured lines, circled on the HR-TEM images (Fig. 2). The eggshells-based HAP exhibited the same surface characteristic, shown in Fig. 2A and $\mathrm{B}$, however the particles appear to exhibit a shorter range order $(\sim 10 \mathrm{~nm})$ compared to the calcite-based HAP $(\sim 40 \mathrm{~nm})$.
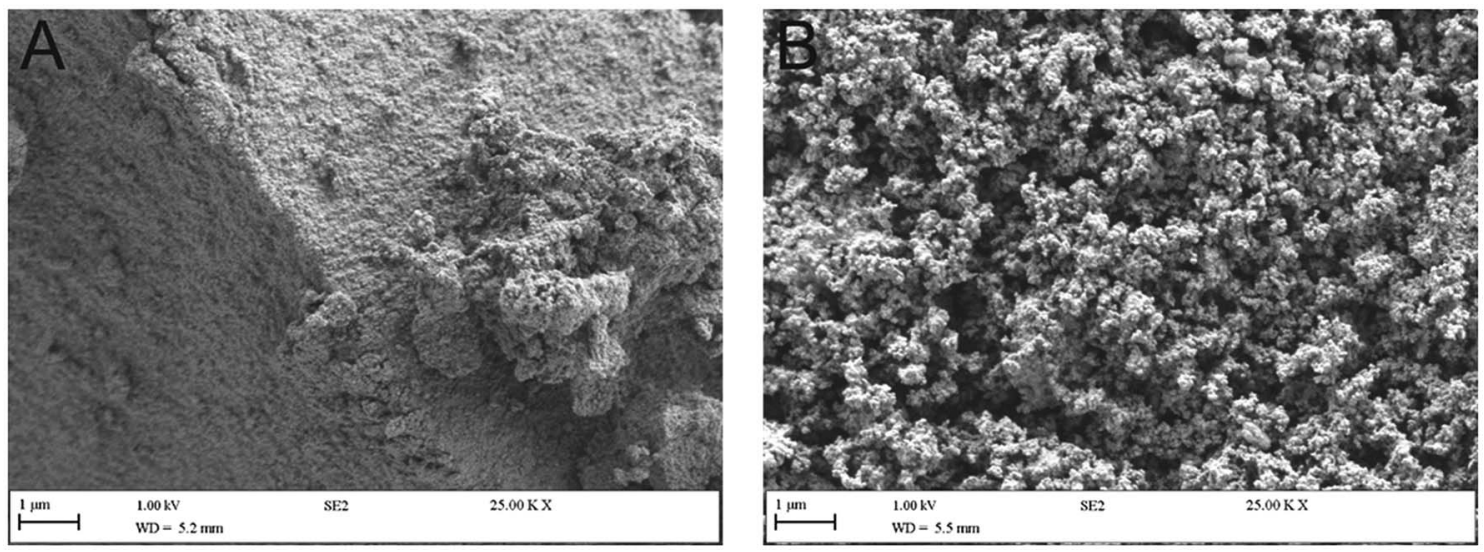

Fig. 1 SEM micrographs of HAP synthesised from (A) eggshells and (B) calcite. 

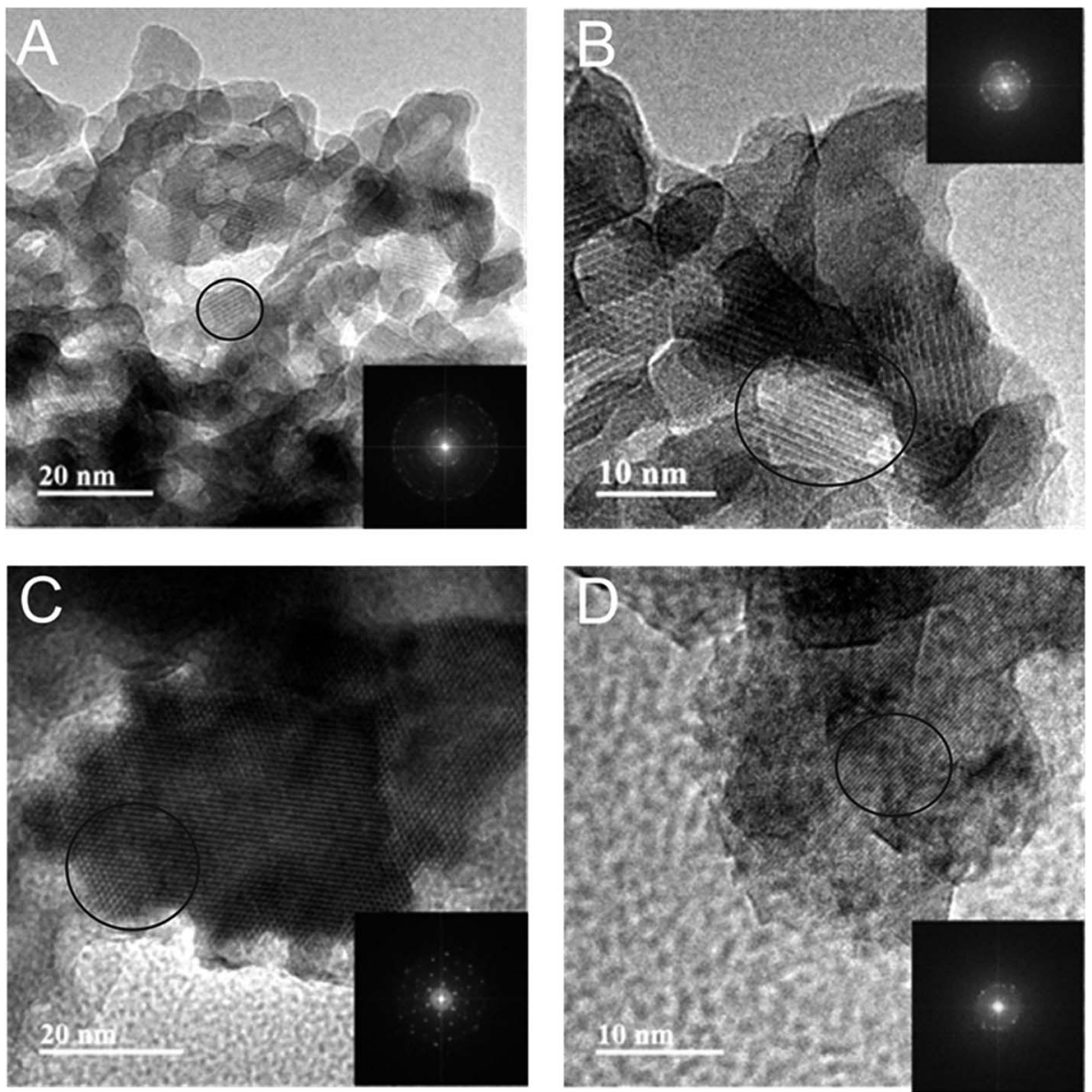

Fig. 2 TEM images of HAP synthesised from eggshells ( $A$ and $B$ ) and calcite ( $C$ and $D)$

Following microscopic imaging, XRD analysis was performed to confirm phase purity of the prepared HAPs. As shown in Fig. 3B, the calcite based HAP was highly crystalline with sharp peaks that resembled the standard diffraction pattern (JCPDS 09-0432). Furthermore, no secondary phases were observed, indicating a highly efficient synthetic process. It is worth noting that the HAP prepared by employing eggshells
(Fig. 3A) revealed a less crystalline structure, observed in Fig. 3A as broader diffraction peaks. Note in this particular application, reduced crystallinity may be more beneficial, since according to Hashimoto and Sato less crystalline materials promote enhanced adsorption capabilities. ${ }^{20}$ FT-IR studies revealed in both cases the characteristics of the HAP phase (shown in Fig. 4), with the main peaks at $1030 \mathrm{~cm}^{-1}$, corresponding to the
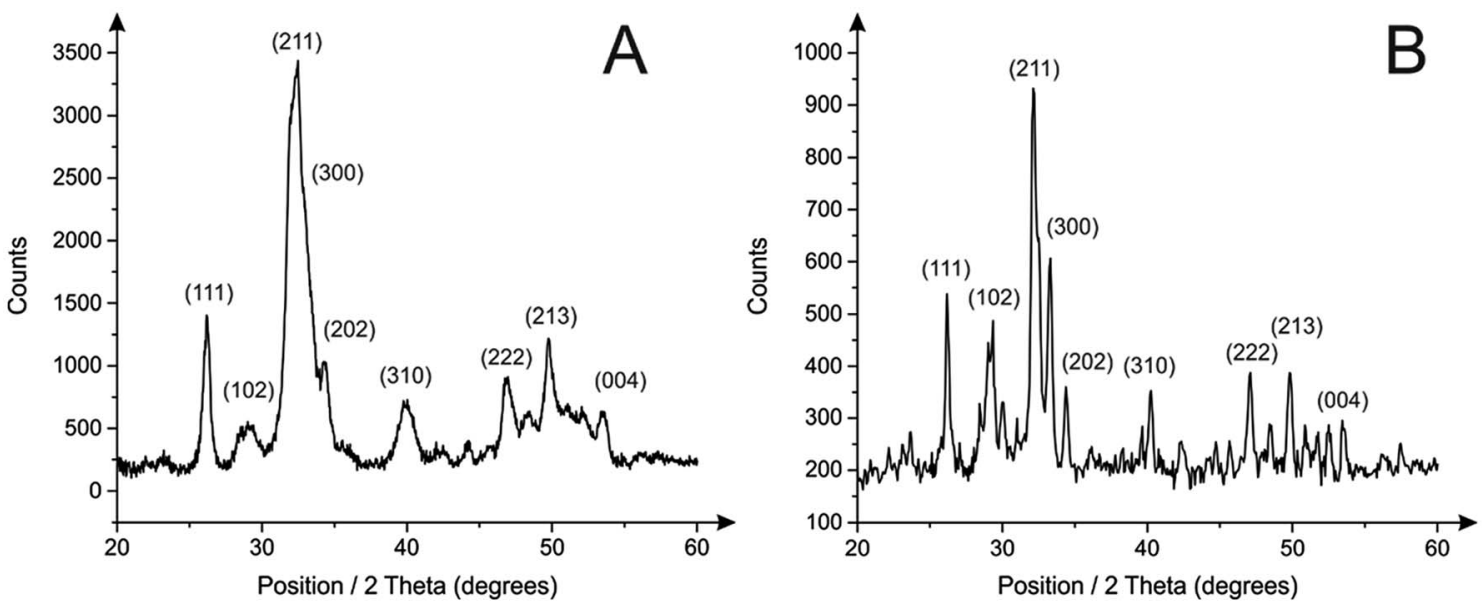

Fig. 3 XRD patterns of HAP synthesised from (A) eggshells and (B) calcite. 
stretching mode of $\mathrm{P}=\mathrm{O}$, a small band at $870 \mathrm{~cm}^{-1}$ indicating $\mathrm{HPO}_{4}{ }^{2-}$ ions, and broad band at $1420 \mathrm{~cm}^{-1}$ typical of $\mathrm{CO}_{3}{ }^{2-}$ species. ${ }^{32}$ It is also worth noting that while the $\mathrm{OH}$ band typical in HAP appears reduced, this is actually a result of the increased intensity of the $\mathrm{P}=\mathrm{O}$ stretching mode. The peaks have been clearly labelled on Fig. 4 for ease of identification.

Subsequently, a nitrogen adsorption isotherm was employed to examine the porosity and pore size distribution of both materials. The BET surface areas of the HAPs corresponded to $45.4 \pm 0.1 \mathrm{~m}^{2} \mathrm{~g}^{-1}$ and $113.4 \pm 0.3 \mathrm{~m}^{2} \mathrm{~g}^{-1}$ for calcite and eggshells-derived HAPs, respectively. This demonstrates that even though there were no additional templates employed in the process, thus keeping the procedure simple, the obtained materials revealed relatively high porosity when compared to that reported in the literature. ${ }^{33}$ In consequence, as presented within Fig. 5A, BJH pore size distribution showed very uniform pores obtained from eggshells-derived HAP with the average diameter of $10 \mathrm{~nm}$. Much bigger and irregular mixture of pores were obtained in HAP that utilised calcite (Fig. 5B) with the average of $53 \mathrm{~nm}$; however the full range of pores present involved both meso- and macro-sized pores. It is worthy to note that even though calcite-derived HAP exhibited a lower surface area, it revealed higher pore volume when compared to eggshells-derived HAP and corresponded to $0.47 \mathrm{~cm}^{3} \mathrm{~g}^{-1}$ and $0.33 \mathrm{~cm}^{3} \mathrm{~g}^{-1}$, respectively. This suggests that during the synthesis calcite promoted formation of an open structure of HAP, which in consequence can be more beneficial for an ion exchange mechanism. ${ }^{12}$

\subsection{Adsorption of lead $\left(\mathrm{Pb}^{2+}\right)$}

Next considered is the efficacy of $\mathrm{Pb}^{2+}$ removal using the assynthesized HAP materials. Batch experiments were carried out to investigate the application of fully characterised HAPs synthesised from waste materials for the removal of $\mathrm{Pb}^{2+}$ from water. In the particular case of $\mathrm{Pb}^{2+}$, it is very well described the suitability of HAP to immobilise this pollutant via cation exchange with the consequent substitution of metal for $\mathrm{Ca}^{2+} \cdot{ }^{20}$ It is also well-known that $\mathrm{pH}$, contact time, initial concentration of metal and mass of adsorbent are important parameters that directly affect the adsorption process..$^{\mathbf{1 0 , 1 9 , 2 9}}$ Therefore, based on the results previously reported in the literature, the kinetic
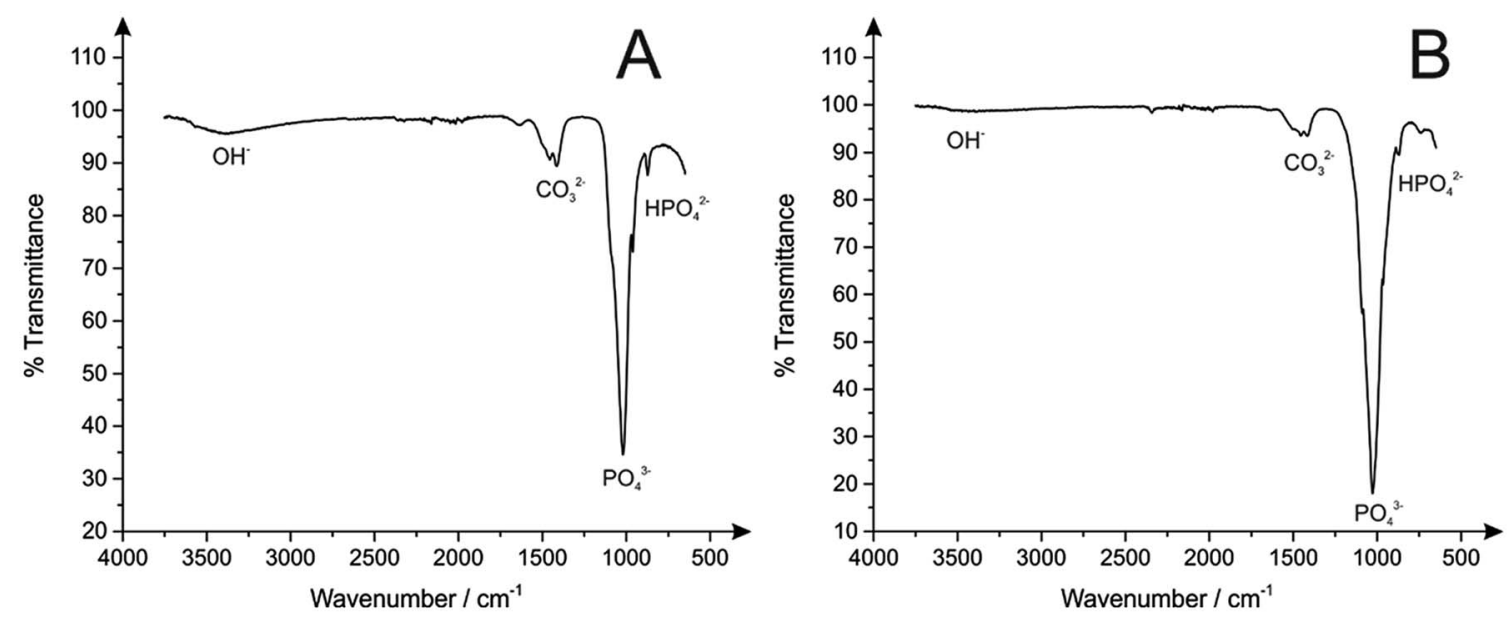

Fig. 4 FT-IR spectrum of HAP synthesised from (A) eggshells and (B) calcite.
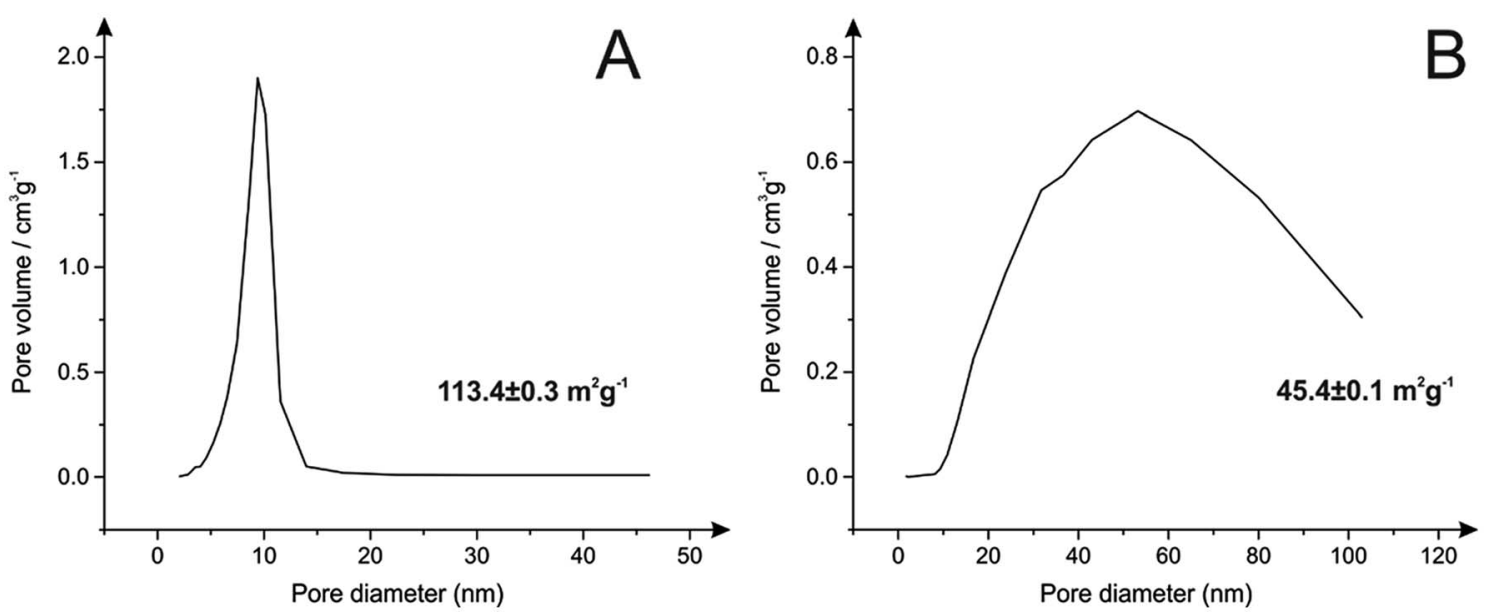

Fig. 5 Pore size distribution and BET surface area HAP synthesised from (A) eggshells and (B) calcite. 
study of the removal of $\mathrm{Pb}^{2+}$ from water using HAP synthesised from eggshells and calcite materials was adapted and performed following the conditions described in the Section 2.5. The adsorption kinetics of $\mathrm{Pb}^{2+}$ on different HAPs were then monitored at $0,5,10,20,40,60,90,120,150,180,240$ and $300 \mathrm{~min}$, respectively.

As represented in Fig. 6, a rapid kinetic reaction of $\mathrm{Pb}^{2+}$ adsorption by both HAPs occurred within the first $5 \mathrm{~min}$. This behaviour was more drastically observed in HAP from calcite,

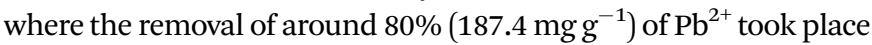
in the first $5 \mathrm{~min}$. Differences in the capability of both HAPs to adsorb aqueous $\mathrm{Pb}^{2+}$ were also clearly observed in Fig. 6. Unexpectedly, HAP synthesised from calcite had a greater rate of adsorption and removed $98 \%$ of $\mathrm{Pb}^{2+}\left(218.6 \mathrm{mg} \mathrm{g}^{-1}\right)$ in $40 \mathrm{~min}$, whilst HAP synthesised from eggshells just achieved 58\% (128.2 $\mathrm{mg} \mathrm{g}^{-1}$ ) within $300 \mathrm{~min}$. These results were unpredicted considering the fact that eggshells are a well-known and reported waste source to perform this synthesis, and also the higher purity of precursor from eggshells and subsequent HAP were assumed more favourable for this application. Also, as reported by Hashimoto and Sato, ${ }^{20}$ poorly-crystalline HAP showed greater capacity for $\mathrm{Pb}^{2+}$ removal than crystalline, so better effectiveness of HAP synthesised from eggshells in the adsorption experiments was expected in contrast with the experimental results obtained. It can thus be proposed from this experiment that the poorer crystallinity of the eggshells-derived HAP cannot explain previous experiments due to the fact that the more crystalline calcite-derived HAP has significantly out-performed the eggshells-derived HAP in terms of cation exchange. This observation is also supported by the sorption kinetic rates calculated for both materials using eqn (2) and
(3). As depicted in Fig. 6B, the $R^{2}$ value of the correlation coefficients indicated that the adsorption of $\mathrm{Pb}^{2+}$ onto both eggshell and calcite-derived HAPs fit the expected pseudo-second order model, where greater linear correlation obtained for calcite HAP explains enhanced efficiency of this material for the adsorption process. Also, the characteristic rate constants $\left(K_{2}\right)$ estimated for both materials after the adjustment to the pseudo-second order model revealed a higher value for calcite-derived HAP. Corresponding calculated values using the pseudo-first order and the pseudosecond order models for the adsorption of $\mathrm{Pb}^{2+}$ on calcitederived HAP and eggshells-derived HAP are summarised in Table 2.

The efficacy of HAP synthesised from calcite compared to eggshell is also demonstrated in Fig. 7, where the timeevolution of the concentration of $\mathrm{Pb}^{2+}$ and $\mathrm{Ca}^{2+}$ in solution is monitored during the adsorption process by using ICP-OES. It was observed that the cation exchange reaction took place during the adsorption process of $\mathrm{Pb}^{2+}$ on HAP synthesised from both waste materials because of a decrease in the concentration of $\mathrm{Pb}^{2+}$ in solution was accompanied with an increase in concentration of $\mathrm{Ca}^{2+}$ from HAP in a similar proportion (Fig. 7A and $\mathrm{B}$ ). Substitution of $\mathrm{Pb}^{2+}$ in the structure of HAP was remarkably more effective in HAP from calcite (Fig. 7B) where a concentration of $5 \mathrm{mg} \mathrm{L^{-1 }}$ of $\mathrm{Pb}^{2+}$ was only remaining in solution after $40 \mathrm{~min}$, demonstrating that the cation exchange process took place favourably on this material. This may be related to the pore volume of the calcite-derived HAP, which was demonstrated to be larger than the eggshells-derived HAP, thus allowing movement of ions in and out of the open structure of HAP more efficiently.
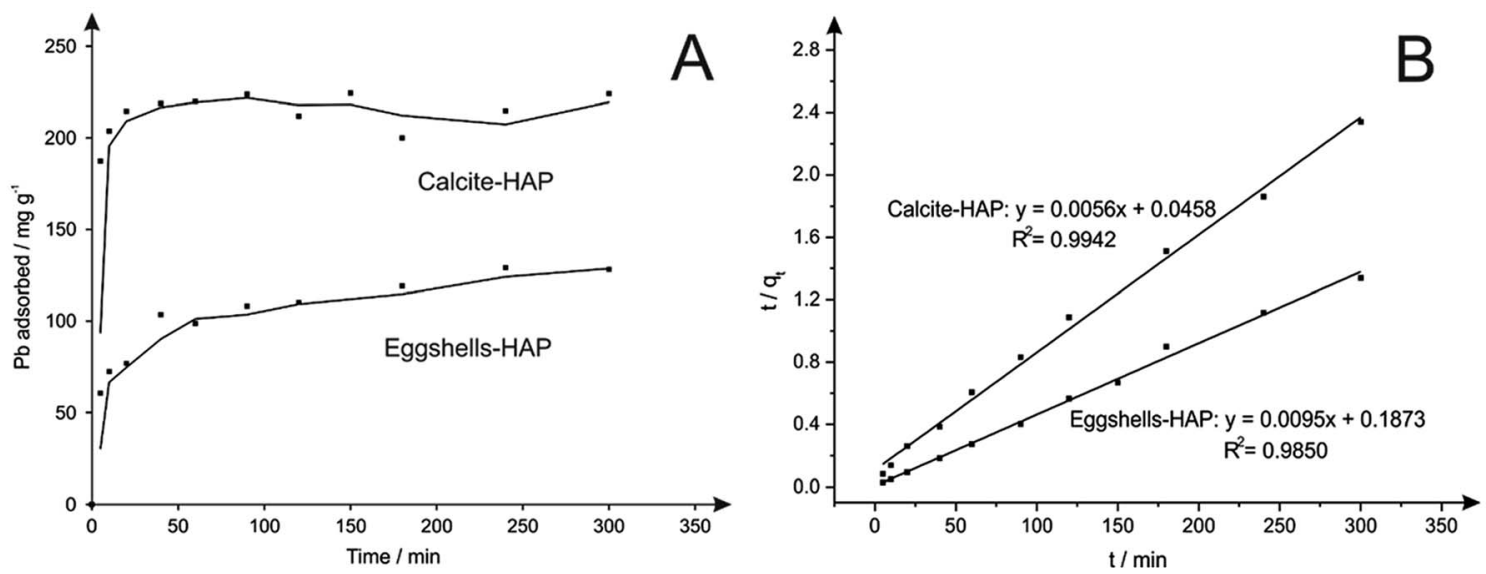

Fig. $6 \mathrm{~Pb}^{2+}$ adsorption kinetics at room temperature on HAP synthesised from eggshells and calcite waste materials (A) and pseudo-second order fit for the adsorption of $\mathrm{Pb}^{2+}$ by calcite and eggshells-derived HAPs at the experimental conditions described in Section 2.5 (B).

Table 2 Calculated parameters using the pseudo-first order and the pseudo-second order models for the adsorption of $\mathrm{Pb}^{2+}$ on calcite-derived HAP and eggshells-derived HAP

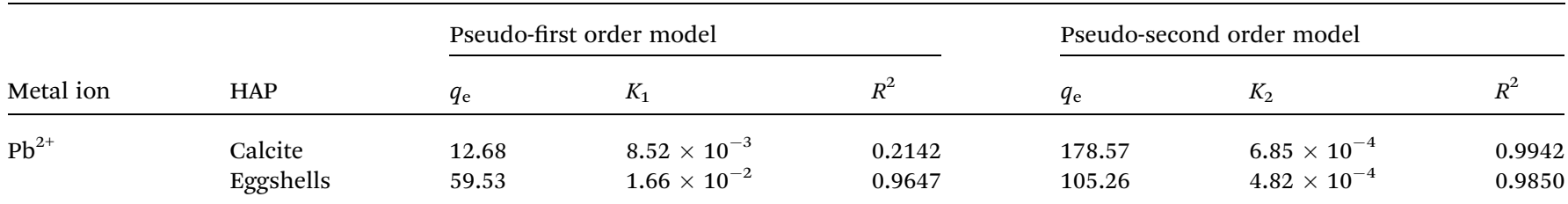



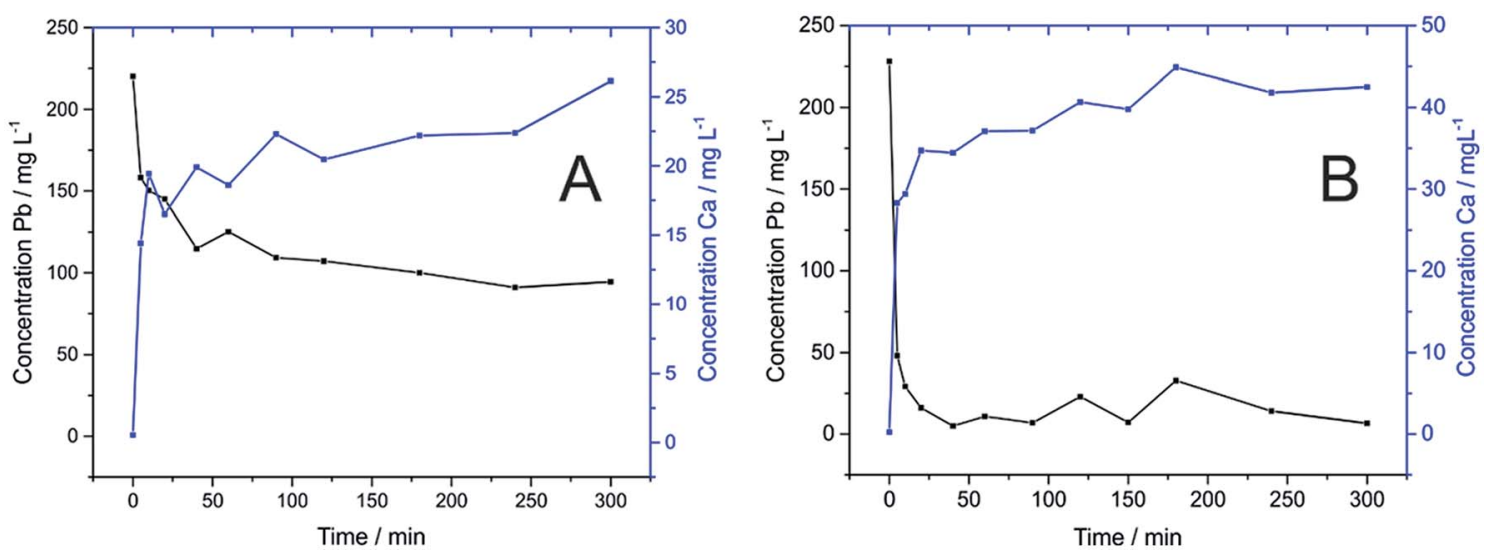

Fig. 7 Time-evolution of the concentration of $\mathrm{Ca}^{2+}$ released from HAP obtained from (A) eggshells and (B) calcite and concentration of $\mathrm{Pb}{ }^{2+}$ remaining in solution during cation exchange-adsorption process.

Finally, the maximum adsorption capacities of HAP synthesised in the present study from calcite and eggshells were calculated using eqn (1) and corresponded to $224.4 \mathrm{mg} \mathrm{g}^{-1}$ and $129.1 \mathrm{mg} \mathrm{g}^{-1}$, respectively. They were similar to those reported in the literature for the removal of $\mathrm{Pb}^{2+}$ using HAP obtained from recycled eggshells $\left(101 \mathrm{mg} \mathrm{g}^{-1}\right),{ }^{10}$ incinerated ash of poultry waste $\left(277 \mathrm{mg} \mathrm{g}^{-1}\right)^{20}$ or flue gas desulfurisation gypsum waste $\left(227.8 \mathrm{mg} \mathrm{g}^{-1}\right) .^{29}$

\section{Conclusions}

This paper, to our knowledge for the first time, has explored the direct valorisation of calcite waste extracted from waste treatment technologies in a simple, rapid and low-cost synthesis of high purity stoichiometric hydroxyapatite via chemical precipitation. The high crystallinity and high phase purity of HAP were confirmed by XRD and FT-IR analysis and were benchmarked against reference HAP derived from eggshells waste simultaneously synthesised following the same procedure. The HAP derived from calcite was successfully utilised for the adsorption of $\mathrm{Pb}^{2+}$ from aqueous media at $\mathrm{pH} 5.0$ by cation exchange and demonstrated an excellent removal efficiency of $\sim 80 \%$ of $^{\mathrm{Pb}^{2+}}$ in the first $5 \mathrm{~min}$, which corresponded to $187.4 \mathrm{mg} \mathrm{g}^{-1}$ of $^{\mathrm{Pb}^{2+}}$. A contact time of only $40 \mathrm{~min}$ was required to reach an equilibrium and remove $98 \%$ of $\mathrm{Pb}^{2+}$ i.e. $218.6 \mathrm{mg} \mathrm{g}^{-1}$. The pseudo-first order and pseudo-second order rate laws were evaluated to investigate the kinetic behaviour and rate constant of initial $\mathrm{Pb}^{2+}$ concentrations. The experimental results demonstrated pseudo-second order fit with the maximum adsorption capacity of $224.4 \mathrm{mg}$ $\mathrm{g}^{-1}$, and a rate constant of $6.84 \times 10^{-4} \mathrm{~g}(\mathrm{mg} \mathrm{min})^{-1}$. This greatly exceeded the value obtained from the reference HAP derived from eggshell waste, where the maximum adsorption capacity was $129.1 \mathrm{mg} \mathrm{g}^{-1}$ and the rate constant was $4.82 \times 10^{-4} \mathrm{~g}(\mathrm{mg} \mathrm{min})^{-1}$. Furthermore, the crystallinity of both the waste calcite material and the waste calcite-derived HAP were demonstrated to be higher than the respective eggshells benchmarking materials. While previous reports suggest crystallinity to be detrimental to $\mathrm{Pb}^{2+}$ adsorption, this work finds no such connection. The preparation of HAP adsorbents via chemical approach using naturally deposited calcite as a calcium source has demonstrated to be remarkably easy and inexpensive alternative to recycle waste materials, opening possibilities of application in the environmental field.

\section{Conflicts of interest}

The authors declare no conflicts of interest within this work.

\section{Acknowledgements}

The authors are thankful to D. McKendry at Manchester Metropolitan University for technical support in ICP-OES analysis. E. Bernalte acknowledges funding from Junta de Extremadura (Spain, PO 14021). E. Randviir would like to thank Stephen Jenkinson, Mike Boulter and Paul Hindley from Greater Manchester Waste for access to the processing site and materials.

\section{References}

1 S. P. Gundupalli, S. Hait and A. Thakur, Waste Manage., 2017, 60, 56-74.

2 H. Müller-Steinhagen, M. R. Malayeri and A. P. Watkinson, Heat Transfer Eng., 2005, 26, 1-4.

3 M. Gruselle, J. Organomet. Chem., 2015, 793, 93-101.

4 N. Gupta, A. K. Kushwaha and M. C. Chattopadhyaya, J. Taiwan Inst. Chem. Eng., 2012, 43, 125-131.

5 M. Vila, S. Sánchez-Salcedo and M. Vallet-Regí, Inorg. Chim. Acta, 2012, 393, 24-35.

6 E. J. M. Edralin, J. L. Garcia, F. M. dela Rosa and E. R. Punzalan, Mater. Lett., 2017, 196, 33-36.

7 J. H. Shariffuddin, M. I. Jones and D. A. Patterson, Chem. Eng. Res. Des., 2013, 91, 1693-1704.

8 A. Shavandi, A. E.-D. A. Bekhit, A. Ali and Z. Sun, Mater. Chem. Phys., 2015, 149-150, 607-616.

9 G. S. Kumar, E. K. Girija, M. Venkatesh, G. Karunakaran, E. Kolesnikov and D. Kuznetsov, Ceram. Int., 2017, 43, 3457-3461.

10 D. Liao, W. Zheng, X. Li, Q. Yang, X. Yue, L. Guo and G. Zeng, J. Hazard. Mater., 2010, 177, 126-130. 
11 S.-C. Wu, H.-K. Tsou, H.-C. Hsu, S.-K. Hsu, S.-P. Liou and W.-F. Ho, Ceram. Int., 2013, 39, 8183-8188.

12 A.-R. Ibrahim, W. Wei, D. Zhang, H. Wang and J. Li, Mater. Lett., 2013, 110, 195-197.

13 S. Nayar and A. Guha, Mater. Sci. Eng. C., 2009, 29, 13261329.

14 A. Shavandi, V. Wilton and A. E.-D. A. Bekhit, J. Taiwan Inst. Chem. Eng., 2016, 65, 437-443.

15 S. Kongsri, K. Janpradit, K. Buapa, S. Techawongstien and S. Chanthai, Chem. Eng. J., 2013, 215-216, 522-532.

16 B. Mondal, S. Mondal, A. Mondal and N. Mandal, Mater. Charact., 2016, 121, 112-124.

17 Y. Liu, Y. Yan, B. Seshadri, F. Qi, Y. Xu, N. Bolan, F. Zheng, X. Sun, W. Han and L. Wang, J. Geochem. Explor., 2018, 184, 239-246.

18 D. Zhang, H. Luo, L. Zheng, K. Wang, H. Li, Y. Wang and H. Feng, J. Hazard. Mater., 2012, 241-242, 418-426.

19 S. M. Mousa, N. S. Ammar and H. A. Ibrahim, J. Saudi Chem. Soc., 2016, 20, 357-365.

20 Y. Hashimoto and T. Sato, Chemosphere, 2007, 69, 17751782.

21 S. Mousa and A. Hanna, Mater. Res. Bull., 2013, 48, 823-828. 22 C. Correas, M. L. Gerardo, A. M. Lord, M. B. Ward, E. Andreoli and A. R. Barron, Chemosphere, 2017, 168, 1317-1323.
23 A. Natali Murri, V. Medri, A. Piancastelli, A. Vaccari and E. Landi, Ceram. Int., 2015, 41, 12811-12822.

24 S.-C. Wu, H.-C. Hsu, S.-K. Hsu, C.-P. Tseng and W.-F. Ho, Adv. Powder Technol., 2017, 28, 1154-1158.

25 T. Takei, N. Imazawa, A. Miura, N. Kumada and K. Ogihara, Powder Technol., 2013, 237, 400-405.

26 J. Chen, Z. Wen, S. Zhong, Z. Wang, J. Wu and Q. Zhang, Mater. Des., 2015, 87, 445-449.

27 S. Patel, S. Wei, J. Han and W. Gao, Mater. Charact., 2015, 109, 73-78.

28 H. Zhou, M. Yang, M. Zhang, S. Hou, S. Kong, L. Yang and L. Deng, Ceram. Int., 2016, 42, 16671-16676.

29 Y. Yan, X. Dong, X. Sun, X. Sun, J. Li, J. Shen, W. Han, X. Liu and L. Wang, J. Colloid Interface Sci., 2014, 429, 68-76.

30 P. J. Harvey, H. K. Handley and M. P. Taylor, Environ. Res., 2016, 151, 275-285.

31 F. B. Reig, J. V. G. Adelantado and M. C. M. Moya Moreno, Talanta, 2002, 58, 811-821.

32 X. Hu, H. Shen, K. Shuai, E. Zhang, Y. Bai, Y. Cheng, X. Xiong, S. Wang, J. Fang and S. Wei, Appl. Surf. Sci., 2011, 257, 1813-1823.

33 S. Ramesh, C. Y. Tan, R. Tolouei, M. Amiriyan, J. Purbolaksono, I. Sopyan and W. D. Teng, Mater. Des., 2012, 34, 148-154. 